information, and more from the ministry officials involved not making use of the available data.

Daniel Rey and Frederico Vilas Martin of the university's department of marine geosciences contend that officials had more than enough data on that part of the Atlantic in November, and other information available to realize that towing the vessel further out to sea would be a recipe for disaster.They said that "the relevant information was [simply] not used."

However, Rey and Vilas Martin think that the ultimate problem is the institutional status quo in Spain regarding scientific research, and the general availability of such research outside the institutions that produce it.

"Bear in mind that $70 \%$ of the international peer-reviewed research papers in Spain come out of universities," they said."And the available scientific and technical information was not used because in Spain, scientific research has a very poor connection with industry and domestic environmental policies."

They contend that government officials "have demonstrated to date that they place very little value on the contributions of our community."
The discontent within the Spanish scientific community was expressed in a letter published in the 24 January issue of Science, in which 422 ocean and atmospheric scientists representing 32 universities and 6 research institutions in Spain-including the University of Vigo-harshly criticized the government's decision-making about the tanker, and saying that the crisis reveals "a serious malfunctiong of the national research system."

Like Rey and Vilas Martin, the signatories blame the disaster on "poor communication between the government officials dealing with the spill and the scientific and technical communities," and they call for an improvement in the mechanisms for scientific and technical consultation between universities and research institutions on the one hand, and government officials on the other.

\section{Early Response Unit Called For}

Rey and Vilas Martin provided more specific ideas about what, in the opinion of their community, the government should do in the scientific realm to avoid a similar disaster in the future. They said that, at present, the Spanish scientific community has the necessary geomorphological and other knowledge, gained from participation in different international research institutes and efforts over the last 30 years; and relevant data, acquired through international efforts such as the International Ocean Drilling Project. But they contend that their material means-ships and instrumentsare still insufficient.

"This needs to be changed," they said.

They also argue for an early response unit to confront environmental risks such as those posed by the Prestige.

Economists, scientists, and other experts from Spain, France, and the United States will be meeting 7-8 March, in Santiago de Compostela, in Galicia, to discuss the experiences of other countries in evaluating the environmental and economic damages from severe petroleum spills, and to try to apply these lessons to the situation along the Galician coast.

\section{—Judy JACOBS, Assistant Managing Editor,Eos}

\title{
Modelers and Geologists Join Forces at Workshop
}

\section{PAGE 79}

The use of geological evidence for climate model evaluation is inevitable. This is clearly reflected by the status of past climatic changes in the latest IPCC Assessment Report (www. ipcc.ch/). Earth System Models of Intermediate Complexity (EMICs) [Claussen et al.,2002] are designed to bridge the gap between simple, conceptual climate models and comprehensive General Circulation Models (GCMs). The big advantage of EMICs lies in their computational efficiency, which allows for long-term climate simulations over several tens of thousands of years. As such, they are reasonable tools for simulating past glacial-interglacial climatic changes. The large number of processes described in the EMICs, even though in a reduced form, enables the user to investigate interactions and feedbacks within the climate system in a broad range of sensitivity experiments.

The use of EMICs can deepen our physical understanding of long-term changes in the paleorecord, and thus of transient changes of the climate system itself. The models help to physically interpret the rather local geological data in a global context. Geological data, in turn, provide us with the only way of verifying climate models. If the models succeed in giving a reasonable picture of the past, their use for assessing future climate change becomes more reliable. Thus, the modeling and data community need to learn from each other's experience.

The need for paleo-environmental data sets for climate modeling purposes is reflected just recently in the emergence of international initiatives like the Data-model Comparison Committee within the framework of the Paleoclimate Modeling Intercomparison Project (PMIP; see
Eos, 1 October 2002). By funding one of the largest research projects ever, (Deutsches Klimaforschungsprogramm, or DEKLIM; www. deklim.de), the German government has also acknowledged the need to foster cooperation between the climate modeling and paleo-data communities. DEKLIM is embedded in the international Climate Variability and Predictability/Past Global Changes (CLIVAR/PAGES) initiative, and a large part of it is devoted to joint data and model investigations of past climates.

\section{The Paleo Workshop}

On the initiative of the EMIC network, a workshop on the Last Glacial Inception was held in Potsdam to foster such interdisciplinary communication and cooperation. The workshop was co-sponsored by the project Climate Change at the Very End of a Warm Stage (EEM).

EEM is one of the DEKLIM sub-projects; it explores environmental changes at the end of the last four interglacial periods and the processes behind these changes, with a focus on the last interglacial (www.uni-mainz.de/FB/Geo/Geologie/sedi/). In all, about 30 participants from 11 institutions attended the workshop, including people involved in the EMICs and in the DEKLIM-EEM community, with Gilles Ramstein representing not only the EMICs, but also the GCM/ PMIP community.

The workshop was one in a series of EMIC workshops that foster model-to-model as well as model-to-data comparison (www.pik-potsdam.de/ claussen/emics/). This time, the discussion topic was the Last Glacial Inception, the period $\sim 116,000$ years B.P., when inland ice built up in parts of North America, Europe, and Asia. This period is also part of phase II of the PMIP activities (see above).
The workshop provided an overview of different paleo-archives and EMIC's activities concerning the Last Glacial Inception in a few selected talks, while also leaving enough room for intensive scientific discussions. As Martin Claussen, the organizer and host of the workshop, said,"We must not only show glossy pictures, but talk about the real challenges, problems, and needs on both the data and the modeling side."

An important result of these discussions was a list of action points that all participants agreed need to be urgently addressed by paleoclimate researchers.

1) Phase-space studies. The question of abrupt transitions and multiple equilibria is of particular interest for future climate change. Some EMICs show a very rapid spread of ice sheets at the Last Glacial Inception, which suggests the existence of multiple equilibrium states. Geologists need to investigate whether the simulated abruptness of changes is reasonable. Modelers should analyze in phasespace diagrams what characteristics determine the bifurcation point, as is done, for example, for the ocean thermohaline circulation and its stability in view of future climate change.

2) Process studies/feedback diagrams. One of the advantages of EMICs is the opportunity to understand the processes behind transient climate changes, as found in the geological record. Model analyses of feedbacks and synergisms, such as those presented by MarieFrance Loutre or Zhaomin Wang, appear as an indispensable method to estimate the relative importance of the individual processes. Modelers are required to elucidate the most important feedback loops operating in their models in the form of feedback diagrams, as André Berger emphasized in his talk. This would allow geologists to apply the model results more easily to their specific record. 
3) Insolation/dating. George Kukla pointed out that it is insufficient and can even be misleading to correlate paleo-data with the summer insolation at $65^{\circ} \mathrm{N}$. Especially for the interpretation of tropical records and leads and lags between the northern and southern hemispheres, a deeper understanding of the driving transient, seasonal, and latitudinal insolation changes, as well as of the role of the individual orbital parameters is inevitable.

Michael Sarnthein's presentation showed that not only are more and larger global data compilations needed to enable data-model intercomparison, but also a common time scale. For modelers, the use of a season definition based on the astronomical position of the Earth (instead of using the present-day length of seasons) is recommended. For the individual archives, the use of a common time scale is often difficult, as discussions on the Greenland Ice Core Project (GRIP) and the Greenland Ice Sheet Project (GISP), on Devil's Hole, or on the orbitally tuned Spectral Mapping Group (SPECMAP) oxygen-isotope record showed. Nevertheless, as the results of Maria Sanchez Goñi and Frank Sirocko impressively demonstrated, a common time scale could easily lead to new insights.

4) Definition of Last Glacial Inception. Finally it should be emphasized that the Last Glacial Inception was discussed as the transition from oxygen isotope stage 5 e to $5 \mathrm{~d}$, and not from stage 5 to 4 .

The workshop participants agreed that keeping the needs of both the paleo-data and the modeling community in mind would be mutually beneficial. The next EMIC workshop will take place in April 2003 along with the EGS-AGU-EUG Joint Assembly in Nice, France.

The EMIC's Workshop on the Last Glacial Inception was held 24-25 October 2002, in Potsdam, Germany.

\section{Reference}

Claussen, M., et al., Earth system models of intermediate complexity, Closing the gap in the spectrum of climate system models, Clim. Dyn., 18,579-586, 2002 .

\section{-Claudia KubatzKi and Martin Claussen,}

Potsdam Institute for Climate Impact Research, Germany

\section{GEOPHYSICISTS}

\section{Nelson Spencer (1918-2002)}

\section{PAGE 82}

Nelson Spencer, former chief of the Laboratory for Atmospheres at NASA/Goddard Space Flight Center, died on 31 August 2002 in Bethesda, Maryland, at the age of 84 due to complications from Parkinson's disease. He had been an AGU member (SPA) since 1950.

He was born in Buffalo, New York, and graduated from the University of Michigan in 1941 with a degree in electrical engineering. Spencer served as a naval officer during World War II and attended Harvard and the Massachusetts Institute of Technology while in the service. After the war, he returned to the University of Michigan for graduate studies, earning his master's degree in electrical engineering in 1953. He soon became director of that department's Space Physics Research Laboratory (SPRL), and later, a full professor. In 1960, Spencer moved to Washington D.C. to lead Goddard's upper atmosphere research effort, serving for many years as chief of the Laboratory for Atmospheres. He retired in 1986.

Spencer made many valuable scientific contributions to aeronomic science, both at Michigan and Goddard.A series of SPRL rocket flights in the late 1950s led to the rather controversial discovery that the daytime ionosphere is not in thermal equilibrium, as had long been assumed by ionosphere theorists. He found that the daytime electron temperature at middle latitudes was typically twice the neutral gas temperature inferred from satellite drag measurements. Even higher electron temperatures were found in auroral regions where particle precipitation provided additional electron heating. These observations inspired new theoretical work on the electron heating and cooling processes that showed that thermal equilibrium indeed should not have been expected. These early results were later confirmed by simultaneous measurements of both the electron and neutral gas temperatures.

Other flights showed that this condition also persists at night at both middle and high latitudes, a result that was later explained by fieldaligned heat conduction from the plasmasphere and magnetosphere. The instruments Spencer developed during the rocket program at Michigan led him to a decades-long satellite exploration of the thermosphere after his move to Goddard. His scientific work there focused on the use of moving baffles in front of neutral gas spectrometers to measure thermospheric temperatures and winds. Used on the Atmosphere Explorers (AE), Dynamics Explorer-2 (DE-2), and San Marco satellites, this method has provided the only global in situ measurements of thermospheric winds and temperature; these data have been used widely in studies of global thermosphere heating and transport.

Spencer's other early contribution to atmospheric research was his ability to promote the idea that aeronomy satellites should be included in NASA's space science program. He was successful in this and became project scientist for several of the missions mentioned above. He was also of enormous help to NASA headquarters in their efforts to establish the Orbiting Geophysical Orbiter program in which he later served as a project scientist. Later, Spencer was successful in gaining approval for the DE satellites, which were to examine the energy coupling between the upper atmosphere and magnetosphere by making simultaneous measurements in both. He also organized the San Marco international satellite program. This was a cooperative effort in which the Italians built the satellites and provided some of the instruments, while U.S. investigators provided other instruments and NASA provided launch services. Spencer was the principal investigator for the wind and temperature experiment on several of these missions.

His atmospheric research interests were not limited to the Earth. In 1970, he joined Richard

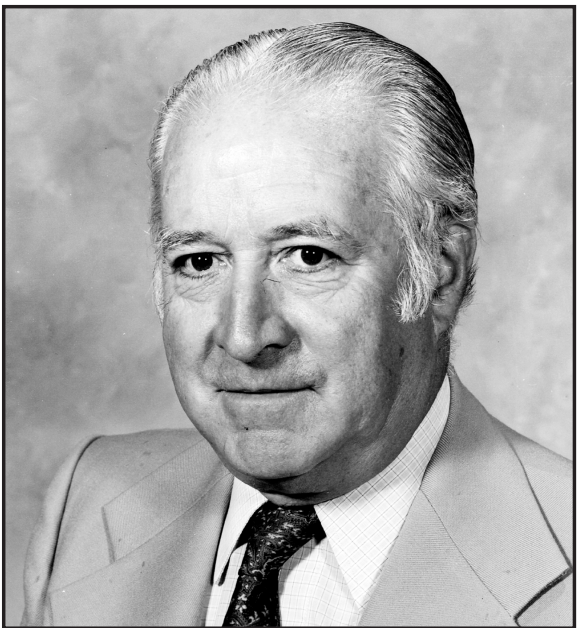

Goody at Harvard and Don Hunten at the University of Arizona to push for NASA approval to conduct aeronomy missions at the other terrestrial planets,Venus and Mars. The goal was to find out why the atmospheres of these planets evolved so differently from that of Earth. Could their differences in composition and temperature be explained simply by differences in their masses, rotation rates, or solar distances? Their efforts led to the approval of the Pioneer Venus project in 1973 and launches in 1978.

This highly successful mission involved a deepdiving orbiter with many in situ and remote measurements, and a second spacecraft carrying an array of entry probes to measure atmospheric temperature and composition all the way to the surface. Sadly, a comparable aeronomy mission to Mars has not yet been conducted, so the hoped-for comparative planetary atmosphere studies remain incomplete.

Another of Spencer's early innovations was the idea that theorists and experimentalists should work together in planning and executing NASA's scientific missions. He implemented this idea by including leading atmospheric theorists as principal investigators in the $\mathrm{AE}, \mathrm{DE}$, and Pioneer Venus science teams. Working in concert with the experimenters, the theorists played a key role in defining the scientific questions to be addressed, the relevant physical parameters, the best instruments, orbits, and data acquisition patterns for the purpose at hand, and then joined 